should be requested to clarify whether or not amphetamines are present in the urine.

MOORE, F. M. L., JARVE, D. R. \& SMPSON, D. (1996) Comparison
of polyclonal and monoclonal tests for routine screening of urine for amphetamines. Annals of Clinical Biochemistry, 33, 78-81.

\section{Loganlea Centre}

76 John Street, Penicuik

Midlothian EH26 8NF

\section{Costing community care}

SIR: We were concerned to read the interesting article by Salize \& Rössler (1996). There is little knowledge of the full costs of community care. They study acute psychiatric patients who are well enough to be discharged into independent living, who thus are not a long-stay population. The costs they quote exclude the costs for accommodation. Therefore, it is not surprising that community care costs less, although $43 \%$ of the cost might be considered high.

We costed the community care placements for a group of long-stay patients discharged into a 24 hour staffed hostel. The residential care for each was $£ 16722.66$ per year, compared with $£ 35000$ for a hospital bed. However, the items included in the hospital price need to be accounted for, such as mental health service input, psychology, occupational therapy and out-patient attendances. When these are added, the total cost comes to $£ 35880$ per resident per year. Drugs ( $£ 700$ per month for the 30 residents of the hostel, excluding depot medication) and primary care are excluded from the above figure.

In conclusion, we agree with Salize \& Rössler that it is vital accurately to cost community care but we wish to draw attention to the even greater importance of comparing like with like. Good, comprehensive community care costs more than hospital care; the most expensive patient in their cohort cost nearly half as much again as an in-patient.

SALIzE, H. J. \& RössleR, W. (1996) The cost of comprehensive care of people with schizophrenia living in the community. A cost evaluation from a German catchment area. British Journal of Psychiatry, 169, 42-48.

A. K. Stanley

Reaside Clinic

Birmingham B45 9BE

St Edwards Hospital

Cheddleton

Staffordshire ST13 7EB

J. F. MaCmillan
R. J. Craig

\section{Cytochromes and psychotropic drug interactions}

SIR: The editorial on cytochromes and psychotropic drug interactions (Taylor \& Lader, 1996) is timely. The recent advances in molecular biology and in the understanding of the cytochrome $\mathrm{p} 450$ system, in particular, need to be brought into the clinical arena. However, the implications of this work go beyond potential drug interactions.

The genotyping of the CYP2D locus has led to the exciting discovery not only of poor and extensive metabolisers but also of ultra-rapid metabolisers of the phenotypic probe, debrisoquine (Johansson et al, 1993). These show one or more copies of the CYP2D6 gene, the expression of which causes the hydroxylation of desbrisoquine (the first step in its breakdown). Since the oxidative metabolism and elimination of most phenothiazines is known to be mediated by the CYP2D6 isoenzyme, there is now a framework to understand patients who are treatment-resistant or who respond only to high levels of antipsychotic medication and appear unaffected by extrapyramidal or other side-effects (Bertilsson et al, 1993). Furthermore, recent studies have found an association between the poor debrisoquine metaboliser phenotype and increased likelihood of extrapyramidal side-effects (Arthur et al, 1995). It may be that once testing becomes more widely available outside specialist centres, genotyping of the CYP2D locus will become commonplace, providing predictive testing for concentrationdependent side-effects such as Parkinsonism, and informing clinical decisions on dosage of antipsychotic medication.

Arthur, H., DhHL, M. L., Stwers, B., et al (1995) Polymorphic drug metabolism in schizophrenic patients with tardive dyskinesia. Journal of Clinical Psychopharmacology, 15, 211-216.

Bertulsson, L., DAHL, M. L., SsoQvist, F., et al (1983) Molecular basis for rational megaprescriping in ultra rapid hydroxylators of debrisoquine. Lancet, 341, 63.

Johansson, I., Lundevist, E., Bertilsson, L., et al (1993) Inherited amplification of an active gene in the cytochrome P450 CYP2D locus as a cause of ultrarapid metabolism of debrisoquine. Proceedings of the National Academy of Sciences USA, $90,11825-11829$.

TAYLOR, D. \& LADER, M. (1996) Cytochromes and psychotropic drug interactions. British Journal of Psychiatry, 168, 529-532.

\section{Parkview Clinic}

G. D. L. BATES

60 Queensbridge Road

Moseley

Birmingham B13 8QE

Queen Elizabeth Psychiatric Hospital

Mindelsohn Way

Birmingham B15 2TZ 